\title{
Hybridization of non-manageable renewable energy plants with compressed or liquefied air storage
}

\author{
Fernando Soto Pérez ${ }^{1}$, Antonio J. Gutiérrez Trashorras ${ }^{1}$, Francisco J. Rubio Serrano ${ }^{2}$ and Jorge Xiberta \\ Bernat $^{1}$ \\ ${ }^{1}$ Energy Department, Escuela Politécnica de Ingeniería, Universidad de Oviedo, \\ 33203, Edificio de Energía Campus de Viesques, Gijón, Asturias, Spain \\ gutierezantonio@uniovi.es \\ ${ }^{2}$ Ibergy S.L. \\ 28223, C/ Salamanca n 25, Pozuelo de Alarcón, Madrid, Spain \\ fjrubio@ibergy.com
}

\begin{abstract}
A kind of energy storage proceeding from renewable sources is presented.

It has been studied the storage, in the form of Compressed Air Energy Storage Systems (CAES) or Liquefied Air Energy Storage Systems (LAES) of the renewable electricity that, at the time it is generated, it is not delivered to the network because of technical or economic reasons, or saturation.
\end{abstract}

The possibility of using an artificial storage system allows the installation not to be conditioned by the availability of a natural reservoir. This article focuses on the use of artificial storage systems, mainly for small power wind farms (about $30 \mathrm{~kW}$ ), so storage systems will alternatively be called CAES or SCAES and LAES or SLAES (S from "small")

CAES systems advantages and disadvantages of each different thermodynamic cycle are studied.

One of CAES systems higher limitations is the huge volume needed to store air mass enough. Instead of storing gaseous phase air, much more energy density can be accumulated by storing air in liquid phase (LAES).

LAES system functioning is similar to CAES one. Liquid air is produced in an air liquefying plant when there is an excess of energy or it is not interesting to drop it into the network

Some LAES systems advantages are storage volume reduction for the same energy density and the possibility of storing at about atmospheric pressure.

Keywords. CAES, LAES, Air, Energy, Storage, Windpower, SCAES, SLAES

\section{Introduction}

The advancement of renewable energies must go hand in hand with the development of ways of storing energy that allow supply to be managed independently of the weather conditions and, in addition, security of supply ${ }^{[1]}$ at competitive prices must be guaranteed in a context of growing international competition for world resources ${ }^{[2]}$.

Optimizing generation through renewable sources involves ensuring that generators supply, on a continuous basis, all the energy capacity (kWh) for which their facilities are designed and that this supply is known in advance by the electrical system operator ${ }^{[3]}$.

It is not enough to substitute fossil fuel power capacity $(\mathrm{kW})$, but also energy availability $(\mathrm{kWh})$. In addition to a reduction and correct allocation of emissions in the sector, a stabilization of the network and a greater use of infrastructures that are designed for certain nominal operating parameters is achieved.

To compensate for the variability of non-manageable renewable energies, not to jeopardize the security of supply and to maintain the balance in the electricity system, what could be taken into account are manageable generation installations, energy storage and international interconnections.

That is why it is particularly necessary to develop energy storages that allow maximizing the use of electricity from renewable sources. 


\section{Technologies for fulfilment instantaneous electricity demand}

It is necessary to provide autonomy from weather conditions to energy generating facilities from nonmanageable renewable sources, so that they are capable of meeting the instantaneous demand by them.

Wind energy is, together with hydroelectric, the most exergetic of renewable energies ${ }^{[4]}$, but nevertheless, and in contrast to hydroelectric, it does not allow by itself to meet changing market demands ${ }^{[5]}$. New ways of making the supply of wind energy manageable are currently being studied.

One of the most promising technologies currently under study, and already in an initial demonstration phase, is obtaining hydrogen by electrolysis of water from wind electricity ${ }^{[6]}$. Obtaining hydrogen will mean the availability of a fuel that can be stored to meet the demand for electricity deferred from the time it is produced ${ }^{[7]}$.

The use of hydrogen as fuel will require that the wind power installation have a support thermal power plant or a fuel-cell. In this way, the market's demand for electricity can be met, either through that obtained directly from wind turbines or through that obtained from the fuel-cell installation or the combustion of hydrogen to drive a steam turbine, a gas turbine or an internal combustion engine ${ }^{[8]}$. The chemical process will only take part when the wind turbines require support to provide $100 \%$ of the installed power.

In the same way as by means of support with hydrogen combustion, the management of the energy supply can be achieved with the installation of a power plant that can also be fed with conventional or alternative fuels, which implies a hybridization also between renewable and manageable energy, an option that can be an interesting transit step, technologically and economically, prior to the use of exclusively renewable energies.

The hybridization between wind and thermal energy would make it possible to verify, under real market conditions, that the supply of electricity from wind farms can be managed in a similar way to conventional systems. This would also mean progress in the future operation of wind power facilities when the next stage in their development is reached, which will probably be the production and storage of hydrogen for combustion for the purposes already indicated ${ }^{[9]}$.

It is important to underline the advantage that means the Hygroscopic Cycle Technology [10] [11] [12] in the support of renewable energy facilities since a thermal power plant can be built wherever it is needed with no limitation due to ambient conditions or water availability. This technology, allows steam to be condensed in dry mode facilities independently of the ambient air temperature (experienced in real conditions in Córdoba, Spain at $48^{\circ} \mathrm{C}$ ambient air temperature) while the efficiency of the thermal plant is increased by taking the steam turbine to the lower vacuum it can reach.

There are other open ways of research whose objective is also to make the supply of electrical energy produced by wind turbines manageable. In areas with suitable orography, surplus wind is used to lift water and thus store potential energy. This system needs to have vast and suitable land for a water storage facility of this type.

Another of the current research ways is to store compressed air that can be released when it is necessary to generate energy in conditions of lack of wind and absence of a wind resource. In this case, the compressed air can be stored in natural cavities in the ground or in specially built tanks close to the wind farm. At present, this type of storage is used almost exclusively in large natural caverns that present the necessary storage conditions suitable for this purpose.

Compressed or liquefied air storage facilities are more flexible, in their hybridization with generation facilities and a renewable energy plant, than conventional generation plants facilities. They can start up as well as raise and lower loads more quickly, and adapt to multiple starts and stops throughout an operating cycle ${ }^{[13]}$.

Some of the possibilities of the hybridization process of a wind farm with energy storage and thermal system support are collected in Figure $1^{[14]}$.

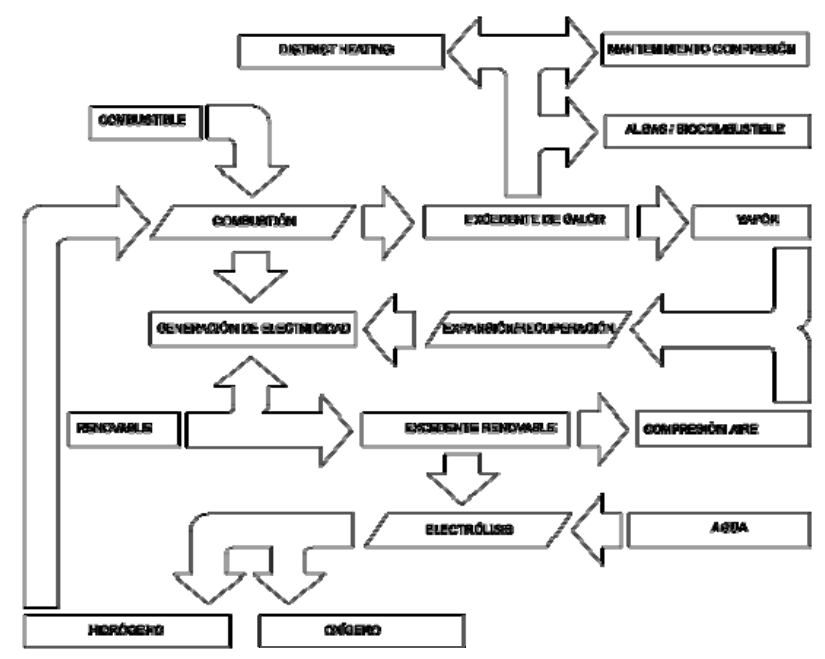

Fig. 1. Hybridization and energy storage process scheme 
In the case of renewable energy sources other than wind, energy storage is also sought and is carried out in other ways, including high temperature molten salt deposits in the case of solar thermal, batteries and electric accumulators in the case of solar photovoltaic, etc.

\section{Compressed air energy storage technologies}

Figure 2 shows operating mode of a CAES system during a 24 hours cycle. The burgundy part of the graph (Stor_D) is the contribution of the CAES system to instant demand ${ }^{[15]}$.

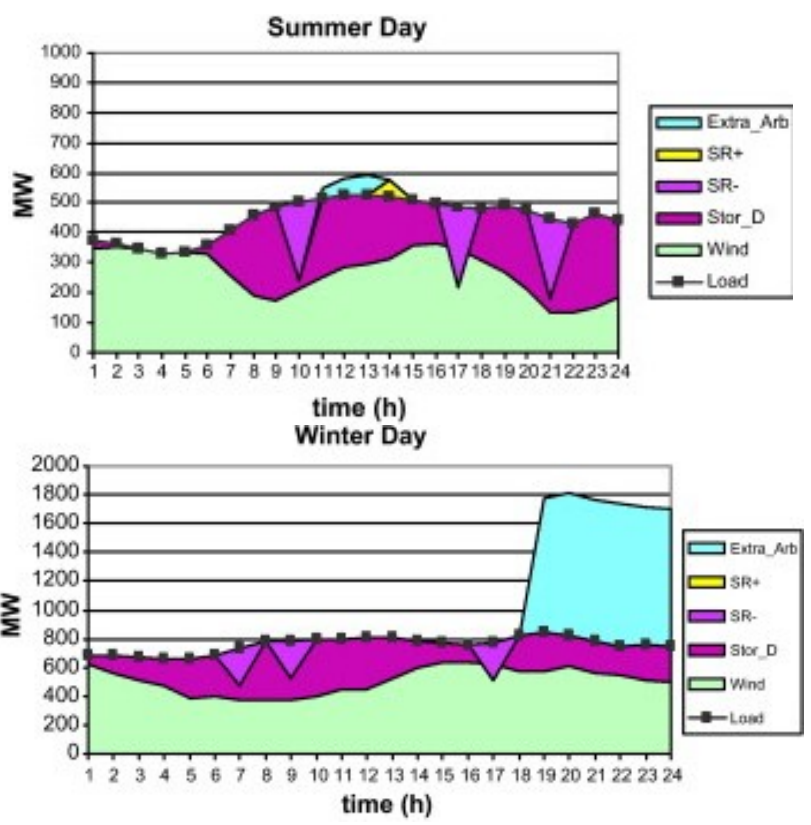

Fig. 2. Operating mode of a CAES system during a 24 hours cycle

\section{A. Diathermic technology}

The diathermic cycle is the one used by the two older compressed air storage power plants currently operating (Huntorf and Maclntosh). It is from this cycle, therefore, that we have the most experimental information ${ }^{[16]}$ (Fig. 3).

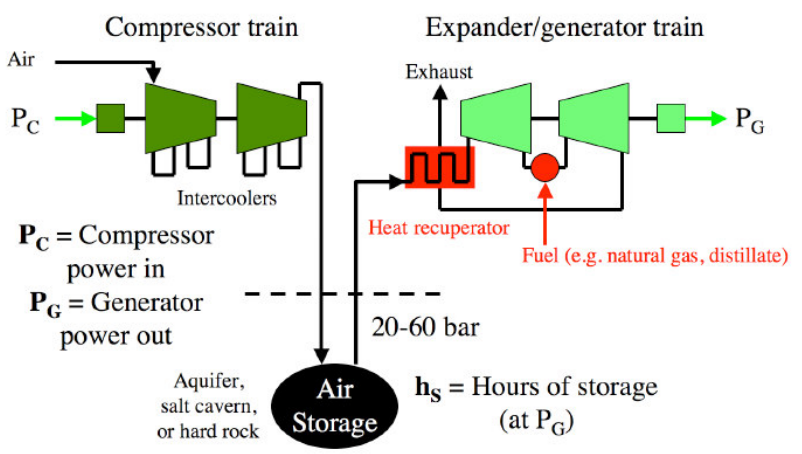

Fig. 3. McIntosh Plant CAES system diagram

\section{B. Adiabatic technology}

Adiabatic CAES technology does not feature heat exchangers at the compressor outlet since the storage is done at compressed air pressure AND temperature. Subsequently, the air is released at an expansion turbine coupled to an electric generator. Nor does it need of the combustion unit of diathermic plants. The lower number of components compared to those reduces thermal losses. However, it requires a good insulation system and sealing to be able to maintain the energy of the compressed air. These systems are currently in the research and development phase ${ }^{[17]}$ (Fig.4).

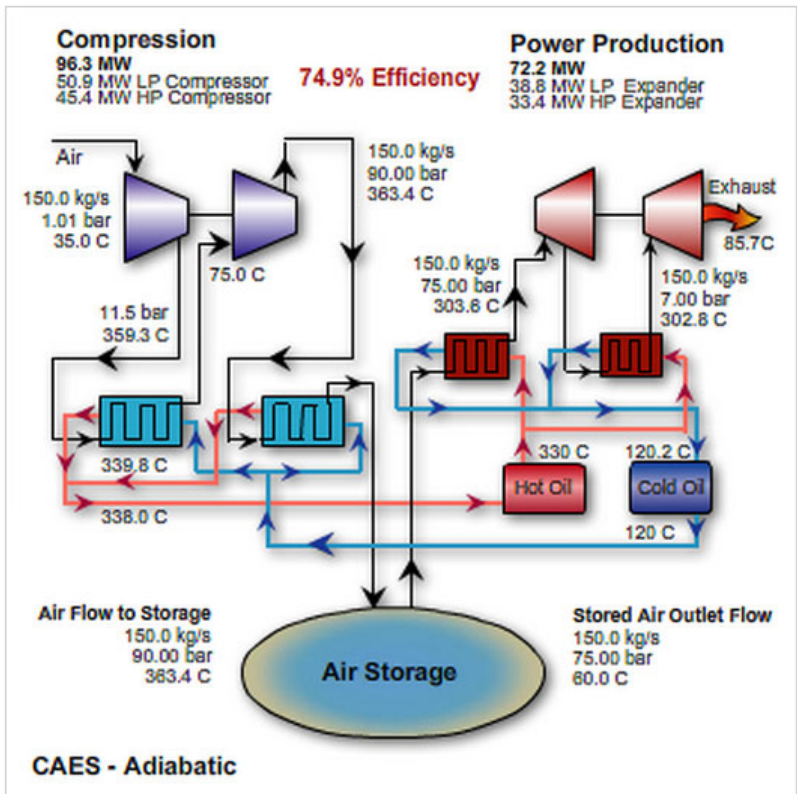

Fig. 4. Adiabatic CAES system by ENERGY STORAGE POWER CORPORATION 


\section{Isothermal technology}

Isothermal type CAES systems are still in the early research and development stage, prior to a demonstration installation. According to its promoters, instead of compressing and expanding the air in turbochargers and turbines, where the process is intrinsically adiabatic, the isothermal system compresses and expands the gas inside hydraulic cylinders, which allows a controlled heat transfer with the environment of the environment during compression and expansion [18]. Thermal performances above $90 \%$ are expected for both compression and expansion.

\section{Obtained parameters for more efficient Wind - SCAES hybrid plant}

Considered options for calculations are a diathermic SCAES cycle with thermal recovery (Fig. 5) and an adiabatic SCAES cycle with pneumatic motor (Fig. 6). Results are later extrapolated to an Adiabatic SCAES cycle with expansion turbine that, at the moment is being developed as a modification of a steam turbine.

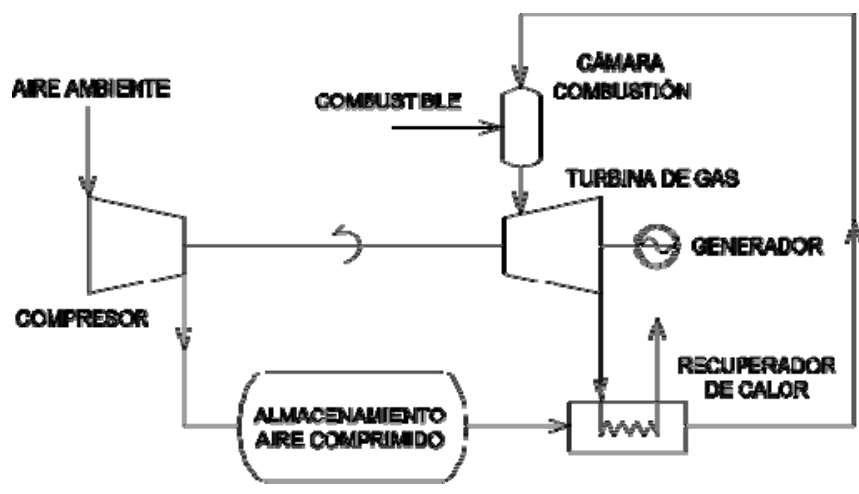

Fig. 5, Diathermic SCAES cycle with thermal recovery

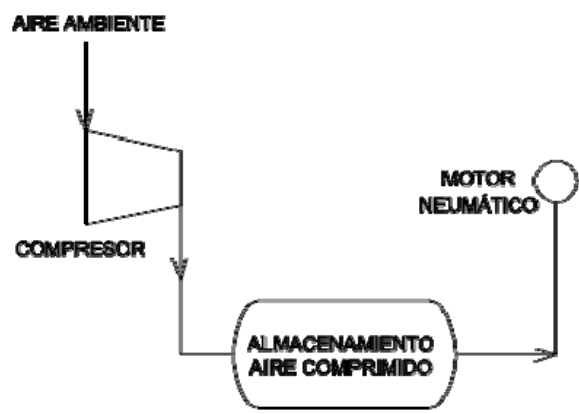

Fig. 6. Adiabatic SCAES cycle with pneumatic motor

From the two studied alternatives, the most advantageous is the adiabatic since it is more efficient, it is simpler, as it does not require a gas turbine or the installation of the fuel for the latter. it has a lower investment and O\&M cost and can operate exclsively with renewable energy. This is why only adiabatic option results are shown (Fig. 7).

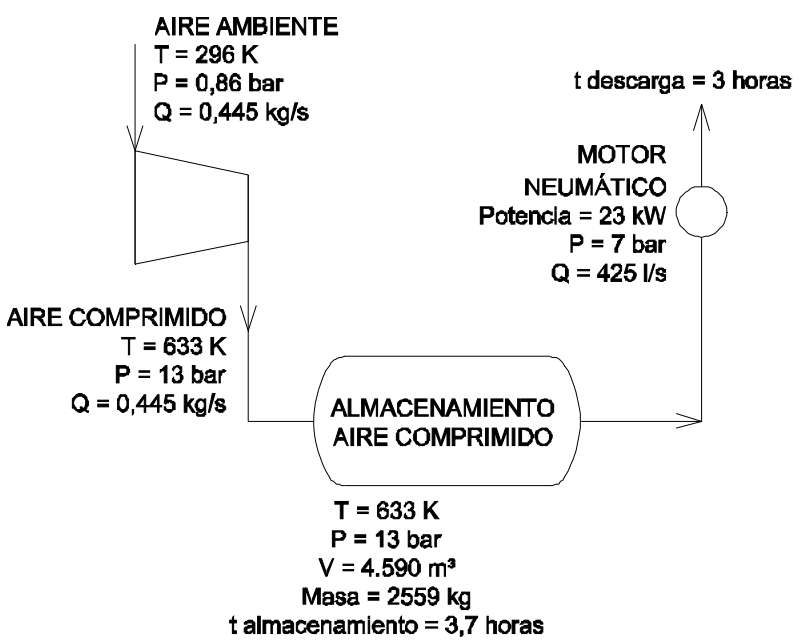

Fig. 7. Results for adiabatic SCAES cycle with pneumatic motor

This system has two problems. The first lies in the storage medium and conduction pipes, which must be built to support high pressure and temperature conditions. The second problem lies in the lack of equipment suitable for operating in defined working conditions: Motors for those pressures and temperatures are not available. The study has been remade considering an expansion turbine (Fig. 8).

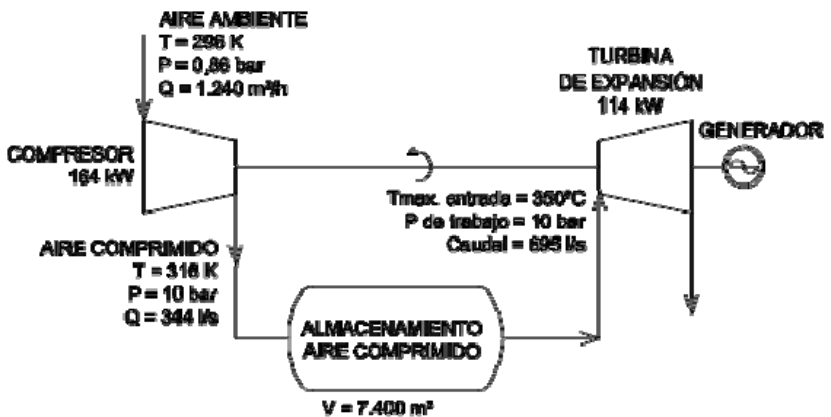

Fig. 8. Results for adiabatic SCAES cycle with expansion turbine

\section{Liquefied air energy storage}

Main limitation of energy storage as compressed air is the large volume needed to store an enough mass of air.

Instead of storing air in the gaseous phase, much higher energy density can be reached by storing air in the liquid phase.

In a CAES system, stored energy density available is about $18 \mathrm{MJ} / \mathrm{m}^{3}$. The energy per unit volume of liquefied air is $660 \mathrm{MJ} / \mathrm{m} 3$, therefore, there is great potential for more compact energy storage ${ }^{[19]}$, since 
36 times less volume is needed to store energy in the form of liquid air than in the form of air in the gas phase ${ }^{[20]}$.

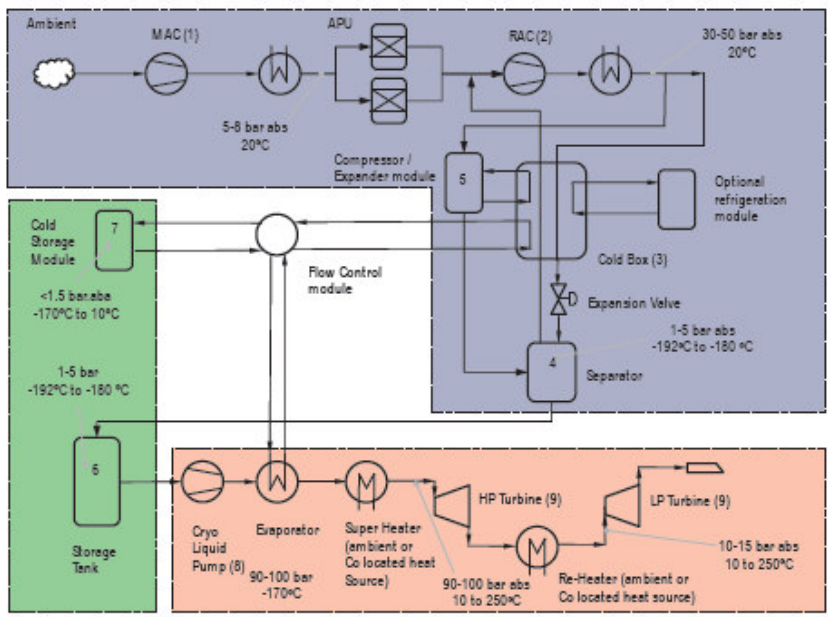

Fig.9. Schematic of a Liquid Air Energy Storage device. Source: Highview Power Storage.

In the case of LAES (Fig.9) the air collected from the environment is compressed and filtered. The water and carbon dioxide are removed so that they do not freeze and block the liquefaction process. The compressed air is cooled and expanded in successive stages so that, in the most part, it is liquefied. The liquefied air is stored in a thermally insulated tank. When it is convenient to generate electricity for its discharge into the grid, the liquefied air is heated by exchanging heat with a fluid with a higher temperature, ambient air, for example, and it is expanded in a turbine system. The air expansion in the turbines follows a Rankine cycle (Fig. 10).

The generation of electricity from stored liquefied air requires the use of the same components that have been considered during the study of the SCAES technologies available for this purpose. The only difference is the chosen storage system.

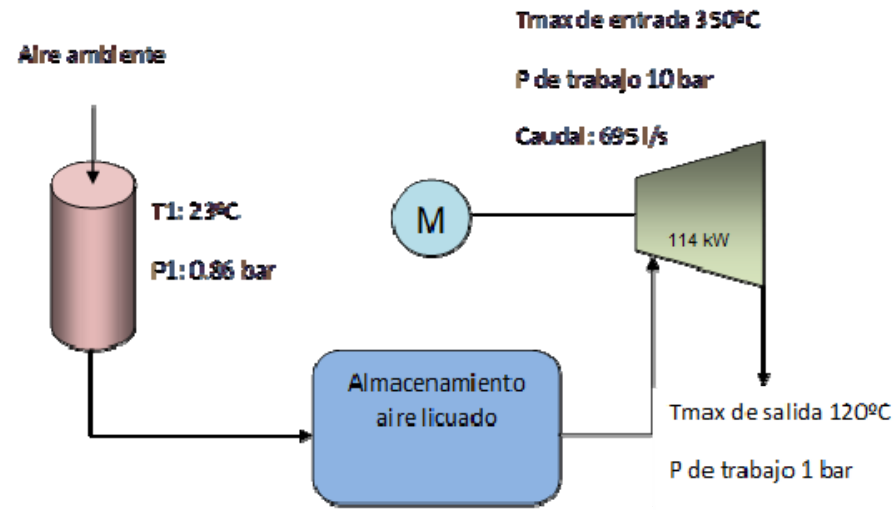

Fig.9. SLAES system with expansion turbine

\section{Conclusion}

The economic SCAES viability of the facility is determined by the following factors:

The cost of storage must be lower than $4 € /$ stored $\mathrm{kW}$. This value is very lower than current.

Compressed calculated storage, is about 40 $\mathrm{m} 3 / \mathrm{MWh}$. The ratio of consumption time in storage versus generation time that makes the installation to be economically viable is $1 / 3$.

In the case of SLAES, calculated storage rate that makes the facility economically viable is approximately $0.07 \mathrm{~m} 3 / \mathrm{MWh}$ and the ratio of consumption time in storage versus generation time that makes the installation economically viable is $1 / 3$.

Energy storage in the form of liquefied air is, for small power generating facilities, more viable economically than energy storage in the form of compressed air.

The independence of facilities equipped with SCAES or SLAES storage systems from external fuels, represents an important strategic value from the point of view of supply assurance. 


\section{References}

[1] LIBRO VERDE. Comisión de las Comunidades Europeas. 2000.

[2] Villicaña-Ortiz, E., Gutiérrez-Trashorras, A. J., ParedesSánchez, J. P. Xiberta-Bernat, J. "Solar energy potential in the coastal zone of the Gulf of Mexico". Renewable Energy, 81. 2015.

[3] Magnus Korpaas, Arne T. Holen, Ragne Hildrum. "Operation and sizing of energy storage for wind power plants in a market system" Electrical Power and Energy Systems. 2003.

[4] Alfred Cavallo. "Controllable and affordable utility-scale electricity from intermittent wind resources and compressed air energy storage (CAES)". ScienceDirect. 2005.

[5] Mathias Zuber (Ecoprog $\mathrm{GmbH}$ ). The World Market for Pumped-Storage Power Plants. 2013.

[6] T. Kousksou, P. Bruel, A. Jamil, T. El Rhafiki, Y. Zeraouli. "Energy storage: Applications and challenges" Solar Energy Materials \& Solar Cells 120. 2014.

[7] J. I. Linares Hurtado, B. Y. Moratilla Soria "El Hidrógeno y la Energía" Colección Avances de Ingeniería. Análisis de situación y prospectiva de nuevas tecnologías energéticas. 2007.

[8] S. Karellas , N. Tzouganatos. "Comparison of the performance of compressed-air and hydrogen energy storage systems: Karpathos island case study". Renewable and Sustainable Energy Reviews 29. 2014.

[9] LINDE annual report 2013.

[10] F.J. Rubio-Serrano, A.J. Gutiérrez-Trashorras, F. SotoPérez, E. Álvarez-Álvarez, E. Blanco-Marigorta, "Advantages of incorporating hygroscopic cycle technology to a $12.5-\mathrm{MW}$ biomass power plant", Applied Thermal Engineer 131, 320-327. 2018.

[11] F.J. Rubio-Serrano, F. Soto-Pérez, A.J. GutiérrezTrashorras, "Experimental study on the influence of the saline concentration in the electrical performance of a Hygroscopic cycle”, Applied Thermal Engineer 165, 114588. 2020.

[12] F.J. Rubio-Serrano, F. Soto-Pérez, A.J. GutiérrezTrashorras, "Influence of cooling temperature increase in a hygroscopic cycle on the performance of the cooling equipment", Energy Conversion and Management 200, 112080. 2019.

[13] Robert H. Schulte, Nicholas Critelli, Jr., Kent Holst, Georgianne Huff. "Lessons from Iowa: Development of a 270 Megawatt Compressed Air"

[14] Fernando Soto Pérez. "Aire comprimido o licuado como almacenamiento de energía”. Editorial Académica Española. 2017.

[15] R. Loisel, A. Mercier, C. Gatzen, N. Elms. "Market evaluation of hybrid wind-storage power systems in case of balancing responsibilities". Renewable and Sustainable Energy Reviews, Vol. 15, issue 9. 5003-50012. 2011.

[16] S. Succar, R. Williams. "Compressed Air Energy Storage: Theory, Resources, and Applications for Wind Power". Princeton Environmental Institute. 2008
[17] www.espcinc.com. Consulted 2021/05/19

[18] James E. Mason, Cristina L. Archer. "Baseload electricity from wind via compressed air energy storage (CAES)". Renewable and Sustainable Energy Reviews 16, 1099 - 1109.. 2012

[19] Bernd Ameel, Christophe T'Joen, Kathleen De Kerpel, Peter De Jaeger, Henk Huisseune, Marnix Van Belleghem, Michel De Paepe:"Thermodynamic analysis of energy storage with a liquid air Rankine cycle". Applied Thermal Engineering, 52, $130-140.2013$.

[20] "Liquid Air in the energy and transport systems. Opportunities for industry and innovation in the UK. Full Report”. The Centre for Low Carbon Futures. 2013 